\title{
INTERNATIONAL LAW AND THE LEGITIMATE DETERMINATION OF RISK: IS DEMOCRATISING EXPERTISE THE ANSWER?
}

\author{
Jacqueline Peel*
}

\begin{abstract}
As technological risks become a matter of increasing concern around the world, standard sciencebased approaches for risk assessment are coming under increasing pressure to be responsive not only to expert views, but also broader public perspectives on risks and concerns over possible uncertainties. International fora in which national risk regulations are reviewed for their scientific adequacy, such as WTO dispute processes under the SPS Agreement, have become the focus for debates over whether such processes allow adequate scope for "democratic" risk concerns as well as scientific views. This article assesses the scope for democratising expertise in international risk determination, using reforms suggested in the context of WTO SPS disputes as a case study. It contends that the institutional ramifications for international law of "democratising expertise" are far from clear, especially given the obstacles encountered in establishing democratic procedures for transparency and participation at the global level. This is not a reason to abandon efforts for greater democratisation of supranational risk determination but points to the need for more nuanced approaches for balancing scientific and political concerns in risk decision-making in order to ensure outcomes which are broadly acceptable.
\end{abstract}

\section{INTRODUCTION}

In democratic societies worldwide, the health and environmental risks posed by technological development are a matter of increasing concern. Standard domestic approaches to the regulation of risky products rely upon processes of expert risk assessment, followed by decision-making on political questions of risk management. Regulatory structures for risk assessment and risk management often maintain a rigorous separation between these processes, citing the need to prevent political interference in the scientific evaluation of risks and (albeit to a lesser extent) the

* BSc/LLB(Hon I), LLM (NYU), PhD (Melb); Senior Lecturer, Faculty of Law, University of Melbourne, Australia. 
desirability of ensuring a distinct space for discussion of non-scientific aspects. Over the last two decades, however, there has been growing recognition that separating science and politics in this way may not allow for an adequate response to complex risk problems that are characterised by scientific uncertainty and divergent community views about risk definition and management. Consequently, there have been increasing calls for, and some domestic experimentation with, "democratising" science and other expert inputs into risk assessment by blending them with nonscientific, value-based information.

As the products giving rise to risk are increasingly traded on a global market, risk problems and their management are also becoming globalised. Emerging international structures for risk decisionmaking - like the dispute settlement system of the World Trade Organisation (WTO) - are being urged to investigate the potential for democratising expertise in the same way as is occurring domestically. In part, such proposals stem from concerns that dominant supranational institutions are using science in an overly narrow fashion, circumscribing the scope for adoption of national risk regulatory measures in response to uncertain or complex risk problems. A focus of discussion in this regard is WTO case law decided under the Sanitary and Phytosanitary Measures Agreement (SPS Agreement), ${ }^{1}$ in which WTO dispute settlement panels and the Appellate Body (WTO-AB) determine the sufficiency of scientific support for a member's risk regulations or the adequacy of any underlying risk assessment. However, also spurring interest in democratisation proposals is the waning power of expertise as a means of providing legitimacy for risk decision-making. Public loss of faith in science poses a particularly critical problem for international bodies making risk determinations since, compared with national governments, they have fewer alternative options for securing social acceptance of their authority.

This article assesses the scope for democratising expertise in international risk determination, using reforms suggested in the context of WTO SPS disputes as a case study. An evaluation of such proposals provides a basis for exploring whether supranational structures, like the WTO dispute settlement system, are well-adapted for making use of democratised expertise, and whether drawing on such expertise might aid in the quest for greater legitimacy of international risk decision-making. As the analysis highlights, there are serious hurdles facing efforts to democratise scientific expertise at the international level given the lack of conventional modes of democratic representation and under-developed participatory structures. However, this is not a reason to abandon efforts for greater democratisation of supranational risk determination, an outcome which might leave in place equally-flawed, narrowly-science focused processes. Rather, it points to the need for greater flexibility in risk decision-making mechanisms employed by supranational bodies like the WTO, so that a balance between scientific credibility concerns and democratic legitimacy can be achieved on a case-by-case basis. The challenge for international risk determination is thus not that of deciding

1 Agreement on the Application of Sanitary and Phytosanitary Measures (15 April 1994) 1867 UNTS 493 [SPS Agreement]. 
between science or democracy, but of finding ways to blend science and non-scientific inputs in order to ensure broadly acceptable outcomes.

\section{DEMOCRATISING EXPERTISE: SOCIAL SCIENCE CONCEPTS}

\section{A Notions of Democratised Expertise}

At the level of theory, let alone practice, the idea of democratising expertise may seem inherently contradictory. Conventional notions of science conceive it as a body of knowledge produced via particular methodologies, whose nature and modes of application are only comprehensible to experts. By contrast, democracy is seen to rest on an alternative premise of all members of a community having an equal right to engage in political discussion and debate. These notions of science and democracy underpin the standard dichotomy between the role of scientific experts as the suppliers of probabilities, impacts and other empirical "facts" (such as in processes of risk assessment), and that of political processes responsible for "value" judgments about the level of acceptable risk (such as in risk management).

Proposals for 'democratising' expertise in the social scientific literature question the feasibility of this separation, especially where risk decision-making is occurring in conditions of scientific uncertainty, or against a background of divergent value positions. For instance, risk assessors often face problems related to ignorance of the workings of natural systems and indeterminacies that can undermine the assumptions scientists make in modelling such systems. While such uncertainties can be quite extensive for many risks, the routines of scientific research tend to disregard them in favour of focusing on more tractable forms of uncertainty that can be addressed through statistical methods and other uncertainty management techniques. ${ }^{2}$ As a consequence, in these circumstances, a seemingly objective determination of the "facts" about a particular risk may easily bleed into "value" judgments about acceptable risk, raising concerns over the democratic authority of scientists to make these decisions. ${ }^{3}$

The democratisation of risk determination attempts to overcome this problem by exposing expert findings to external public scrutiny. The "democratic" procedures drawn on for this purpose tend to be ones in the liberal proceduralist tradition, which emphasise processes for ensuring transparency, deliberation and public participation in decision-making as the basis of legitimate authority. Such notions of democracy are also those best-adapted to citizens' monitoring of processes of risk determination since the highly technical nature of such decisions means that they are often delegated to administrative decision-makers who are not directly accountable to those

2 Brian Wynne "Science and Social Responsibility" in Jake Ansell and Frank Wharton (eds) Risk: Analysis, Assessment and Management (John Wiley, Chichester, 1992) 137, 141.

3 Paul Stern and Harvey Fineberg (eds) Understanding Risk: Informing Decisions in a Democratic Society (National Academies Press, Washington, 1996). 
affected. ${ }^{4}$ In essence what is being articulated through the notion of "democratised expertise" are new broader visions of science - ones that acknowledge the potential for uncertainty, as well as the ways in which scientific knowledge is shaped by social and cultural influences where uncertainties are prevalent. These newer versions of science seek to strengthen its utility as a resource for risk decision-making by making it more cognisant of areas of ignorance and indeterminacy, and hence more aware of the potential for human activities to have unforseen consequences. Another common feature of such broader notions of science is the call for greater attention to "the normative that lurks within the technical" so that value-laden aspects of scientific risk assessment are made explicit and opened up to critical discussion. ${ }^{5}$

Through the application of democratic procedures of transparency, deliberation and participation to expert findings, conventional forms of scientific research and assessment are exposed to a greater range of perspectives, thus bringing science "into the public debate along with all the other issues affecting our society". ${ }^{6}$ In this way, scientific risk assessments may be supplemented by various forms of knowledge held by non-scientists. This knowledge serves as a means for identifying the deficiencies of expert assessments in circumstances of uncertainty, and ensuring that the values influencing the risks selected for assessment are more broadly representative of public views. For those with a strong allegiance to positivist scientific traditions, such calls for democratisation are often misconstrued as a challenge to the central role of science in health and environmental regulation or as a threat to the credibility of risk determinations. However, democratisation of expertise does not involve "turning over the research labs to untrained persons", ${ }^{7}$ or denying scientific assessments of risk any role in the process of risk determination. Rather, the underlying rationale of democratising expertise is one of better equipping science for the policy settings in which it now finds itself by strengthening it against critiques that it has overstepped its conventionally narrow role as a supplier of relevant facts. Hence, democratising expertise can be viewed as a means for ensuring the continuing relevance of science for risk decision-making, even in complex or contested situations.

\section{B Models for Democratising Expertise}

Reflecting the developing nature of scholarship on the democratisation of expertise, various approaches have been proposed in the social-scientific literature. There are some commentators

4 Peter Lindseth "Democratic Legitimacy and the Administrative Character of Supranationalism: The Example of the European Community" (1999) 99 Columbia L Rev 628.

5 Sheila Jasanoff "Technologies of Humility: Citizen Participation in Governing Science" (2003) 41(3) Minerva 223, 240.

6 Silvio Funtowicz and Jerome Ravetz "Three Types of Risk Assessment and the Emergence of Post-Normal Science" in Sheldon Krimsky and Dominic Golding (eds) Social Theories of Risk (Praeger, Westport, 1992) 251,254

7 Ibid. 
who, while acknowledging the need for risk decision-making to be responsive to public concerns, contend that enhancing accountability for the outcomes of such processes depends as much upon science disciplining politics as politics disciplining science. Consequently prominent scholars, such as Cass Sunstein, argue that in the area of health and environmental regulation efforts should be made to increase the use of technocratic tools, such as quantitative risk assessment and cost-benefit analysis, on the basis that they systematise the process of risk-decision-making and render it transparent to the public. ${ }^{8}$ Along similar lines are proposals for improved risk communication, which are designed to mediate divergences between scientific and public perspectives on risk (most commonly) through experts educating the public about the "true" nature of risks. ${ }^{9}$ While such proposals are at one end of a possible continuum of diverse approaches for democratising expertise, they still tend to depend heavily on conventional notions of science conceived as a body of knowledge capable of sharp demarcation from the political domain. In circumstances where that boundary is blurred, (such as where intractable uncertainties arise) more transparent processes might ameliorate some of the deficiencies of science-based decision-making but cannot make it value neutral. Indeed, persistence with such approaches may only serve to reduce the credibility of science as a resource for risk assessment, ultimately undermining public support for resulting decisions.

Those approaches which, by contrast, seek to make science a more "socially robust" contributor to risk decision-making recognise that its knowledge claims need to demonstrate "validity outside as well as inside the laboratory", are "most likely to be achieved by involving an extended group of experts" and will generally result "from having been repeatedly tested, expanded and modified."10 Producing such knowledge requires "genuine debate on the way a problem is formulated, knowledge is developed and uncertainties are dealt with" within a framework that envisages a more extensive role for participants beyond the traditional domains of expertise. ${ }^{11}$ Some commentators see existing regulatory concepts that emphasise scientific uncertainty, such as the precautionary principle, as appropriate for housing such an approach. ${ }^{12}$ Other models for democratising expertise also take the difficulties of risk decision-making under conditions of uncertainty as a departure point but propose new approaches. For example, Funtowicz and Ravetz's model of "extended peer

8 Cass Sunstein Risk and Reason: Safety, Law, and the Environment (Cambridge University Press, Cambridge, 2002) 294.

9 Carlo Jaeger and others Risk, Uncertainty, and Rational Action (Earthscan, London, 2001) 127.

10 Helga Nowotny "Democratising Expertise and Socially Robust Knowledge" (2003) 30(3) Science and Public Policy 151, 155.

11 Angela Liberatore and Silvio Funtowicz "'Democratising' Expertise, 'Expertising' Democracy: What Does this Mean, and Why Bother?" (2003) 30(3) Science and Public Policy 146, 147.

12 For example, Theofanis Christoforou "The Precautionary Principle and Democratizing Expertise: a European Legal Perspective" (2003) 30(3) Science \& Public Policy 205. 
review" urges the use of "an extended peer community" in risk assessment, employing "extended facts" such as anecdotal evidence and statistics gathered by community members. ${ }^{13}$ For others the way that questions are selected and framed for risk assessment is at least as important, if not more important, than the way such questions are subsequently assessed. ${ }^{14}$ Here the critical focal point for democratisation is the scoping exercises undertaken at the outset of risk assessment that determine what harms and uncertainties are of importance; processes which are often dominated by experts despite the normative content of these questions.

In practice there are many overlaps between these various models of democratised expertise. A common feature of many is a reliance on improving the transparency of risk assessment and avenues for participation by those outside the conventional sphere of regulators and their expert advisors, not just when it comes to political judgments about acceptable risk but also in decision-making about what risks and uncertainties are assessed. Depending on the particular model adopted, democratisation might serve to allow a broader initial framing of risk questions, a more comprehensive response to uncertainty, or a means for obtaining public input into value-laden questions raised by risk decision-making regarding harms of concern and their relative significance.

\section{DEMOCRATISING WTO SPS RISK DETERMINATION}

\section{A SPS Jurisprudence: Science-based Risk Determination}

While explicit discussion of democratised expertise models is rare outside the social science literature, the same intellectual inspiration can be seen as informing an increasing number of proposals in legal literature suggesting reforms to supranational risk decision-making, especially that of the WTO dispute settlement system in SPS cases. Like their social science counterparts, these legal commentators start from the premise that science as a sole basis for risk determination is problematic in conditions of uncertainty or where there exist divergent perspectives on risk drawn from different socio-political or cultural traditions. The WTO SPS Agreement and case law decided under it have attracted particular attention because of the requirements for WTO members to ensure that any SPS measure "is based on scientific principles and is not maintained without sufficient scientific evidence", and further that "sanitary or phytosanitary measures are based on an assessment, as appropriate to the circumstances, of the risks to human, animal or plant life or health". ${ }^{15}$ In the event that a WTO dispute is initiated by one member over the SPS measures adopted by another, the matter is brought initially before a three-member WTO panel, with a right of appeal on legal questions to the WTO-AB. WTO decision-makers in such cases undertake a review of the respondent member's SPS risk regulations and determine whether there is an adequate

13 Funtowicz and Ravetz, above n 6, 254.

14 For example, Brian Wynne "Risk and Social Learning: Reification to Engagement" in Sheldon Krimsky and Dominic Golding (eds) Social Theories of Risk (Praeger, Westport, 1992) 275.

15 SPS Agreement, above n 1, articles 2.2, 5.1. 
scientific basis for the measures. The emphasis placed on scientific justification for risk regulation in the SPS Agreement is viewed with concern by some commentators, given the potential for a narrowly science-focused supranational review to restrict the scope for national measures to respond to situations of more complex, uncertain risks. ${ }^{16}$

These concerns have been borne out by WTO jurisprudence under the SPS Agreement, which in a series of cases has developed progressively narrower understandings of what amounts to sufficient scientific evidence and an adequate risk assessment for SPS purposes. The restrictiveness of these notions was displayed in the recently-issued rulings of the WTO Panel in the EC-Biotech case, involving a challenge to the European Community's (EC) regulatory scheme for managing the potential health and environmental risks of genetically modified organisms (GMOs). ${ }^{17}$ The dispute generated considerable controversy because it pits different GMO regulatory approaches against one another: a "sound science" approach (favoured by the complainants in the dispute) and a "precautionary" approach that advocates caution in the face of scientific uncertainties and political debate over the nature and significance of possible GMO risks. Divisions over GMO risks have arisen within the EC, as well as internationally, leading a number of EC Member States to introduce safeguard measures prohibiting the use of certain GMOs in their territories despite assessments by EC-level scientific committees finding the products currently pose no risk. EC Member states and others who advocate a precautionary approach to GMO risk regulation point to various scientific studies suggesting the potential for GMOs to cause health or environmental harms or raising questions over the utility of current data for predicting long-term adverse effects.

In assessing this evidence and its adequacy as a risk assessment for SPS purposes, the $E C$ Biotech Panel rigidly applied previous rulings of the WTO-AB to the effect that SPS risk assessments must evaluate the probability (and not the mere possibility) of harm in a comprehensive fashion and relying on studies that deal specifically with the risk situation at issue. The Panel's application of these tests suggested that it was searching for "a complete, self-contained, scientific evaluation" of particular GMO risks in order to conclude that risk regulatory measures were supported by an adequate risk assessment. ${ }^{18}$ Entirely lacking from the Panel's review, however, was any enquiry as to the adequacy of the current science to provide the basis for such assessments of the likely health and environmental effects of particular GMOs. Indeed, the Panel's conclusion was that available scientific evidence was sufficient for the purpose of assessing health and

16 For example, David Wirth "The Role of Science in the Uruguay Round and NAFTA Trade Disciplines" (1994) 27 Cornell Int'l LJ 817; Jan Bohanes "Risk Regulation in WTO Law: A Procedure-Based Approach to the Precautionary Principle" (2002) 40 Colum J Transnat'l L 323; Oren Perez, Ecological Sensitivity and Global Legal Pluralism: Rethinking the Trade and Environment Conflict (Hart, Portland, 2004).

17 EC - Measures Affecting the Approval and Marketing of Biotech Products Reports of the Panel (29 September 2006) WT/DS291/R, WT/DS292/R, WT/DS293/R. [EC-Biotech].

18 Ibid, para 7.3188 . 
environmental risks because EC-level scientific committees had been prepared to issue, and later reaffirm, favourable risk assessments of the products subject to safeguard measures. ${ }^{19}$ These findings raise questions over the capacity of WTO SPS review of national risk measures to allow scope for the full consideration of uncertainty in risk assessment and to recognise that risks might be assessed differently depending upon whether all societies frame the risks of concern in the same way.

\section{B Proposals for Democratising WTO SPS Review}

Although united by concerns as to the impacts of narrowly science-focused review on national SPS risk regulation, legal commentators' suggestions for reform have varied in nature. The proposals put forward generally emphasise the importance of risk determination being based on more than "just science" in order to garner credibility and legitimacy in democratic societies. In most cases, this is more than a simple plea for national regulatory autonomy in an age of globalisation, with explicit attention being paid to the competing concerns of domestic and supranational systems. It is this aspect of the proposals that makes them an interesting focus for analysis as they highlight the kinds of institutional obstacles that will need to be grappled with if international risk decision-making is to give effect to notions of democratised expertise. Far more so than calls for global risk determinations to be based on sound science, the proposals also expose the "hard" decisions thrown up by the frequent need to rely on "soft" science in health and environmental risk assessment. As such, while they may not provide all the answers, they at least indicate many of the important questions that will need to be asked in the design and implementation of supranational risk governance.

\section{Strategies of deference}

When processes for international supervision of risk decision-making were first introduced into instruments like the SPS Agreement, forward-thinking commentators remarked on the potential for highly intrusive review of risk regulations, taking insufficient account of the fact that "science may inform the regulatory process but cannot, by itself, determine the result with particularity". ${ }^{20}$ WTO decision-makers reviewing domestic risk measures were thus adjured to "be highly deferential to scientific determinations of national authorities that underlie regulatory measures to protect the environment and public health." ${ }^{21}$ Proposals of this kind continue to find favour with some commentators a decade or so later. ${ }^{22}$ On its face, supranational deference would seem to have much

19 Ibid, para 8.9.

20 Wirth, above n 16,833

21 Ibid, 859

22 Andrew Guzman "Food Fears: Health and Safety at the WTO" (2004) 45 Virginia J Int'l L 1; Theofanis Christoforou "Settlement of Science-Based Trade Disputes in the WTO: A Critical Review of the Developing Case Law in the Face of Scientific Uncertainty" (2000) 8 NYU Environmental LJ 622. 
to recommend it, not least being that it largely avoids the problems incurred in seeking to democratise scientific inputs to supranational risk decision-making processes by assuming that uncertainty and broader risk concerns are adequately taken into account in the domestic regulatory system.

In the WTO SPS case law, however, arguments for deference raised by members have not met with a favourable response. The WTO-AB has pointed to the requirement for a panel to make "an objective assessment of the matter before it" as ruling out an approach to assessing the scientific sufficiency of SPS measures in light of a Member's own evaluation of the scientific evidence. ${ }^{23}$ In a trade forum, this reaction to a call for deferential review might be attributed simply to the suspicion with which strict health and environmental (and especially precautionary) regulatory measures are frequently viewed, given assumptions of regulatory capture. Indeed, there may be a legitimate foundation for caution given that the conditions under which science is a deficient tool for risk assessment are also those which may promote its exploitation by governments for instrumental purposes, either to erect trade barriers, or to further an anti-regulatory agenda. However, a more fundamental difficulty with a strategy of deference is that it would seem to relinquish possibilities for encouraging national authorities to be more cognisant of the effects of their measures on individuals, businesses and communities in other countries. Instilling such other-regarding practices among domestic regulators may even be seen to have a "democracy-reinforcing" effect by improving the accountability of state-based risk regulation to all those who might be affected by it. $^{24}$

Of course there may be some categories of health or environmental risk (or at least risks at certain stages in the course of knowledge and experiential evolution regarding them) which are best excluded from international review and decision-making processes, and left instead to the individual judgment of different, domestic regulatory authorities. A differentiated, deferential approach in WTO judicial review of SPS measures is advocated, for instance, by Button. She proposes a "standard of review hinging on reasonableness" as a means to ensure that "a defending member is meeting its substantive commitment only to take regulatory action where there is scientific justification without unnecessarily intruding into the national regulator's assessment of the significance of various pieces of scientific evidence or its integration of social and cultural factors into the regulatory process". ${ }^{25}$ As Button points out, the principal value of such an approach is that it may illuminate the multi-dimensional, complex nature of risk questions and invite a more

23 Japan - Measures Affecting the Importation of Apples Report of the Appellate Body (26 November 2003) WT/DS245/AB/R, para 165 .

24 Joanne Scott "European Regulation of GMOs: Thinking about 'Judicial Review' in the WTO" (2004) Jean Monnet Working Paper 04/04 www.jeanmonnetprogram.org (accessed 1 March 2007) 13.

25 Catherine Button The Power to Protect: Trade, Health and Uncertainty in the WTO (Hart, Oxford, 2004) 235. 
contextualised assessment by "concentrating the panel's mind on the fact that it is reviewing a regulatory action and not a disembodied set of facts." ${ }^{26}$ However, left unclear by such a proposal is how WTO decision-makers might evaluate the "reasonableness" of particular uses of science, especially given the lack of normative guidance in this regard. As Button herself observes, the institutional structures of the multilateral trading system are ones lacking a clear vision regarding "what type of group the WTO is and what it wants to achieve". ${ }^{27}$

\section{Broadening the range of participants}

At the other end of the spectrum from proposals advocating deference to national risk decisionmaking are those which focus on opening up supranational processes like WTO dispute settlement to a wider range of participants. These proposals meld with the rationale of democratising expertise to the extent that they provide opportunities for broadening the available information base for risk decision-making. From the perspective of enhancing the legitimacy of WTO risk regulatory review, they are also seen to play a useful role by allowing decision-makers to draw on the knowledge of those with expertise in a particular area. Under the WTO SPS Agreement, there is already a provision of this kind, allowing reference to experts in the course of disputes, although the focus is on obtaining "scientific and technical" advice. ${ }^{28}$ There is, however, nothing to prevent WTO panels making more imaginative use of this provision, for example, by soliciting expert advice relating to other bodies of knowledge in fields like the agricultural and social sciences. It might also provide an avenue for greater inter-institutional cooperation and multilateral engagement by encouraging WTO decision-makers to consult with broadly-based international organisations in the United Nations system.

From an institutional perspective, the advantage of broadening the notion of expertise as a means for democratising WTO SPS dispute settlement is that it is relatively easy to accommodate within existing legal structures. Of course, simply providing panels and the WTO-AB with a broader range of expert opinion is no guarantee that that information will actually be taken into consideration. The recent Panel decision in the EC-Biotech case illustrates this only too well, with the Panel making few references to the extensive expert advice compiled over the course of the dispute and dismissing the information put forward in amicus briefs filed by a range of nongovernmental organisations (NGOs) because it "did not find it necessary to take the amicus curiae briefs into account."29 Moreover, involving more experts in WTO SPS risk decision-making may not be sufficient to capture knowledge existing outside the expert domain (for example, that held by industry, NGOs or community members) nor to prevent the imagination block that may be

26 Ibid, 221.

27 Ibid, 211.

28 SPS Agreement, above n 1, article 11.2.

29 EC-Biotech, above n 17, para 7.11. 
engendered by always looking at risk problems through an expert lens. There is thus a danger that reliance on bodies of experts to better inform WTO panels in relation to relevant risks and uncertainties may simply become another layer of "technocracy", albeit one that canvases a greater range of views. ${ }^{30}$

In addition, a consensus achieved by experts may not necessarily be indicative of a wider social consensus on the most appropriate ways of framing the risks concerned. This argues for making available an even broader information base to those undertaking risk decision-making in supranational institutions like the WTO; one that includes public views on a given risk issue, which can then be used to challenge expert framings of risk and uncertainty. Conceivably this information might come in the form of surveys of public or consumer opinion. For some, however, the objections that can be raised to such an approach "are so numerous and so intense that it may be misconceived to even contemplate travelling down this road." 31 After all, consumer and public opinion are notoriously difficult to survey accurately, both because of their constantly evolving nature, and due to the difficulties of designing mechanisms that capture the diversity of views that exist in any society. In a trade context, there are also significant concerns about the manipulation of consumer opinion, not least through the creation of regulatory distinctions between different products contributing to public perceptions of riskiness.

Some of these difficulties might be obviated by allowing direct participation by individuals or groups in WTO risk decision-making processes. Such participatory mechanisms are a feature of the risk regulatory systems of Western democracies and some have been in place for number of decades. However, domestic experience would appear to provide an unstable basis for constructing similar participatory mechanisms for supranational risk determination. Not only is there presently limited understanding, at the theoretical level, regarding what makes an effective public participation mechanism, but also practical problems arise as a result of the lack of sufficient specialised knowledge and material resources available to the general public. In addition, warnings about the potential perils of participation, drawn from domestic systems that have placed a premium on transparency in risk decision-making, should not be ignored. Jasanoff points to consistent findings in empirical research that "transparency may exacerbate rather than quell controversy, leading parties to deconstruct each other's positions instead of deliberating effectively." 32 Contestation of broadly accepted international risk management practices in some of the SPS

30 Steve Rayner "Democracy in the Age of Assessment: Reflections on the Roles of Expertise and Democracy in Public-Sector Decision Making" (2003) 30(3) Science and Public Policy 163, 169.

31 Scott, above n 24, 26.

32 Jasanoff, above n 5, 237. 
disputes on the basis of different possible interpretations of the available scientific data seem to bear out the relevance of this concern for risk decision-making in an international context. ${ }^{33}$

Transposing participatory mechanisms to supranational structures, like those of the WTO, may only seem to invite an exacerbation of the problems uncovered domestically, given that greater divergences of interests and values are likely. Further, proposals for direct participation by individuals or groups raise new and difficult questions as to who is the relevant public for a particular risk determination made at the supranational level. Delimiting the relevant addressees of the decision of a supranational institution like the WTO is made more complex by the absence of global political structures and constituencies that might aid in determining those affected. ${ }^{34}$ In recent times, it has been other actors better capable of operating at the supranational level, such as NGOs, which have purported to voice the concerns of the public internationally. In recognition of their public interest role, reforms to allow greater NGO participation in international fora have gained significant momentum in the last decade, including the acceptance (albeit rarely the substantive consideration) of amicus curiae briefs from NGOs in WTO disputes. ${ }^{35}$ Nonetheless, proposals for greater NGO involvement, for example, as advisors to, or complainants before, panels in WTO disputes, face a barrage of criticisms, the most intractable of which relate to NGOs' representativeness of wider public concerns, especially those of the developing world. Quite apart from these concerns, there is also little guarantee that institutional reforms to enhance NGO participation would favour increased exposure of WTO decision-makers to public risk perspectives over those of professional groups or business organisations, which are often better placed to take advantage of participatory mechanisms.

Although many are reluctant to foreclose the possibility entirely, the theoretical and practical difficulties in embracing a role for public opinion or local knowledge inputs in WTO risk decisionmaking remain serious. Simply grafting public participation procedures onto risk decision-making mechanisms cannot be expected to produce an automatic democratisation of the underlying science. Moreover, exposing decision-makers to a broader range of views about risk will serve little purpose if non-scientific information is consistently overlooked in favour of seemingly more objective inputs. Hence participatory reforms, if they occur, will need to be accompanied by a wider change

33 Jeffrey Dunoff "Lotus Eaters: The Varietals Dispute, the SPS Agreement, and WTO Resolution" in George Bermann and Petros Mavroidis (eds) Health Regulation in the WTO (Cambridge University Press, Cambridge, 2006) 153.

34 Ruth Grant and Robert Keohane "Accountability and Abuses of Power in World Politics" (2005) 99(1) American Political Science Review 29, 34.

35 US - Import Prohibition of Certain Shrimp and Shrimp Products Report of the Appellate Body (12 October 1998) WT/DS58/AB/R, para 89 paved the way for the acceptance of amicus briefs by NGOs. 
to the "culture of governance" in supranational institutions such as the WTO, which pays attention not just to "the mechanics, but also to the substance of participatory politics." 36

\section{Procedural review}

The drawbacks of a simple deference approach, and the institutional challenges of harnessing a wide range of risk perspectives at the international level, have spurred the development of more nuanced democratisation proposals that attempt to strike a balance between "localized science policy decision-making" and global assessments of risk. ${ }^{37}$ Common to such proposals is the view that faith in science as an objective arbiter of risk is misplaced and, in any event, poses difficult problems for international decision-makers charged with evaluating the truth of divergent risk claims. Nonetheless, it is recognised that, left to themselves, domestic risk regulatory authorities, even (or especially) in democratic societies, are likely to accord insufficient regard to the risk perspectives of those outside of the national polity. Hence a compromise is proposed whereby domestic authorities would retain competency over the substantive evaluation of risks, while the role of supranationally-located WTO reviewers would be to focus on the regulatory process followed by those authorities and whether it allows for an adequate consideration of different views about risk. ${ }^{38}$ In the SPS context, this would mean that a national risk determination could not be evaluated simply on the basis of its consistency with a narrowly-focused science-based risk assessment. Rather the task of the WTO dispute settlement organs would be to assess the way in which scientific and other inputs were gathered and evaluated in reaching decisions on SPS risk. The adequacy of this process might be judged against criteria of inclusiveness (were all relevant risk perspectives - scientific, economic, and public - considered?), transparency (were the reasons for the ultimate decision explained?) and intellectual rigour (were scientific inputs peer-reviewed and subjected to open and critical discussion?). ${ }^{39}$

Procedural review of science-based decision-making is an approach which has similarities with judicial review practices seen in national risk regulatory systems, such as that of the United States. ${ }^{40}$ Nonetheless, the lessons of domestic experience do not unequivocally demonstrate the superiority of procedural over substantive review of science-based decision-making. There is no guarantee that

36 Jasanoff, above n 5, 238 .

37 David Winickoff and others "Adjudicating the GM Food Wars: Science, Risk, and Democracy in World Trade Law" (2005) 30 Yale J Int'l L 81, 111.

38 For a recent example of how such a model might operate in practice see Methanex Corporation $v$ USA (2005) 44 ILM 1345, Part IIIA, para 101

39 For example, Robert Howse "Democracy, Science, and Free Trade: Risk Regulation on Trial at the World Trade Organization" (2000) 98 Michigan L Rev 2329, 2330; Bohanes, above n 16, 365-370; Perez, above n $16,154-55$.

40 Winickoff and others, above n 37, 110. 
procedural indicators of an appropriately deliberative process will be handled any more sensitively by WTO decision-makers than the substantive criteria offered by science (as the EC-Biotech Panel's overly robust treatment of the EC's justifications for delay in the face of scientific and regulatory complexities demonstrates). ${ }^{41}$ The difficulty facing a review of risk regulatory process, as much as for an assessment of the scientific justification for the resulting measures, is that normative judgments are still required in order to determine what amounts to an "adequate" process.

While simply shifting the focus of WTO review in SPS disputes from matters of scientific substance to those of regulatory process will not do away with the need for difficult value judgments about risk, it may be possible to construct a framework around the decision-making process that enhances the legitimacy of its outcomes. In this regard, the proposal put forward by a quintet of distinguished social science professors in a recent article on the EC-Biotech dispute provides important insights as to how democratisation of supranational risk assessment might be effected in a way that both addresses concerns over the credibility of science-based evaluations in uncertain or contested risk scenarios, and also buttresses the legitimacy of WTO risk decision-making. ${ }^{42}$ Winickoff and others, in common with other proponents of procedural approaches, believe that WTO SPS review should generally "steer away from adopting any member state's conclusions as scientific truths" and instead "act more as an administrative tribunal searching for transparency and procedural adequacy". ${ }^{43}$ However, key to their proposal is the notion that the balance between substantive and procedural review can be determined in light of the characteristics of the risk situations at issue. They see two aspects of risk situations as critical in this respect: the level of certainty surrounding a risk (which can be determined in light of the available knowledge base and the analytic methods to be applied in assessing risks) and the degree of social consensus regarding risk (which relates to the framing of the scientific issues to be addressed and the values to be protected through public policy). According to the authors, risk situations can be conceptualised on a "continuum", running from "low certainty and low consensus" at one end, to "high certainty and high consensus" at the other. ${ }^{44}$ Factors that would allow WTO decision-makers to locate risk situations on this certainty-consensus continuum would include the relative novelty of the technologies or activities with which risks may be associated, whether it has been possible to agree upon international standards relating to those risks, the degree to which unknowns affect current knowledge of, or methodologies for, assessing risks, and the extent to which evidence sourced in the

41 EC-Biotech, above n 17, para 7.1490 and following.

42 Winickoff and others, above $\mathrm{n} 37$.

43 Ibid, 107.

44 Ibid, 104. 
literature, regulatory experience or public dialogues suggests a lack of consensus and certainty as to the nature, sources, and extent of the risks involved. ${ }^{45}$

Winickoff and others argue that in cases of low certainty and low consensus, public input into the risk decision-making process assumes both social and scientific importance in order to "frame risk in ways that make regulation more relevant and effective" and "present the relevant questions that need to be answered before risks are assumed". ${ }^{46}$ Hence, in low (or even medium) certainty and consensus situations, they believe this should invite a "more deferential approach to the sciencebased decision-making of members," giving national regulators greater room "to take public value choices into consideration when setting appropriate regulatory standards." 47 Nonetheless, the authors acknowledge that in cases where consensus and certainty are high, "the range of rational measures to address the risk situation should be more limited."48 Accordingly, while their approach seeks to grant broader scope for the consideration of particularised public concerns in SPS risk decision-making, they recognise that "in situations of high consensus and high certainty, a heavier burden will be placed on [WTO] members to establish that their measures stem from nonprotectionist values." 49

While undoubtedly there would be those who would contend that supranational deference is never justified in respect of national risk regulatory processes with cross-border impacts (particularly where detrimental effects are likely to be borne predominantly by exporters in developing countries), what is significant about the approach put forward by Winickoff and others is that it emphasises the need to assess such competing normative claims in light of the characteristics of the risk situation at hand. In the framework they propose, the normative claims of locally-based risk concerns would only be given greater weight via mechanisms of procedural review in circumstances of low certainty and significant social disagreement over health and environmental risks. Put another way, this approach uses measurable, defensible criteria relating to the particular risk situation being addressed as a means for determining, on case-by-case basis, the balance struck in decision-making between competing considerations of scientific credibility and political legitimacy. In this sense, the proposal offers an example of how, in the context of SPS judicial review, democratisation of the process could enhance both the legitimacy of WTO risk decisionmaking (by making it more sensitive to public risk concerns) and yet minimise the potential for arbitrary (or unfair) decision-making. Of course, the challenges that this approach poses for international decision-makers may not be limited merely to the mechanics of decision-making

\footnotetext{
45 Ibid, $115-116$.

46 Ibid, 105-106.

47 Ibid, 117-118.

48 Ibid, 118.

49 Ibid, 123.
} 
processes. At issue may also be the culture underlying interpretative practices, which in respect of WTO SPS decision-making has been one that continues to display a virtually unshakeable faith in the possibilities for resolving complex disputes by reference to apolitical expertise.

\section{CONCLUSION: NEGOTIATING A SCIENCE-DEMOCRACY BALANCE}

Notions and models of democratised expertise being developed in the social scientific literature offer a means for responding to many of the limitations posed by an over-reliance on science and science-based risk assessment in complex and uncertain risk situations. Applied in supranational contexts like WTO decision-making in SPS disputes, such notions could provide a more credible and legitimate basis for determinations of what the WTO-AB has referred to as "risk in human societies as they actually exist". ${ }^{50}$ Particularly where uncertainties or disputed risk framings are an issue, models for democratising expertise present ways of supplementing scientific knowledge used in risk assessment so that it can better take account of unknowns and the different values at stake in health and environmental regulation. Importantly, they also provide a means for strengthening science to make it more robust in an environment where it is continually asked "to transgress the boundaries between specialised knowledge and its multiple, many-layered (and often unforeseeable) context of implication". 51

Moving from theory to the practice of supranational risk decision-making is the difficulty that now presents itself. This challenge is one that is currently being grappled with in the legal literature, such as that proposing reforms to WTO dispute settlement processes in SPS disputes. On a review of the proposals that have been put forward to date there would seem to be many objections. For example, if deference is accorded to national or local risk preferences in WTO review, legitimate concerns may be raised as to whether this comes at the expense of the value concerns of those outside of the polity or, indeed, whether national risk preferences are really driving a decision or merely being used as cover for less worthy motives. A proposal for particularised risk decisions of domestic authorities to receive WTO-level deference only if they are made in a transparent fashion and are open to challenges from outsiders may not fully address the criticisms of those who are sceptical of the adequacy of such procedural safeguards, especially where interested actors have unequal capacities to monitor and participate in the vast array of contemporary risk decision-making processes.

Attempts to create more direct avenues for involvement of non-standard knowledge and nonexpert participants in WTO SPS decision-making also encounter difficulties. Reasonable questions may be raised in relation to the legitimacy and authority of WTO decision-makers to judge the importance of different value concerns, the relevance of different framings of risk, or the plausibility

50 EC - Measures Concerning Meat and Meat Products Report of the Appellate Body (16 January 1998) $\mathrm{WT} / \mathrm{DS} 26 / \mathrm{AB} / \mathrm{R}$ and WT/DS48/AB/R, para 187.

51 Nowotny, above n 10, 152. 
of various policy responses in the face of scientific uncertainty. If, on the other hand, WTO decision-makers seek to inform themselves more widely as to relevant risk perspectives and value concerns, the institutional structures within which they must operate are not well-adapted to gathering such information directly from individuals or groups, rather than from national governments. All these concerns point to the difficulties of implementing democratised forms of risk assessment in WTO SPS dispute settlement, and supranational structures more broadly; difficulties which are often more serious in comparison with those faced by similar domestic-scale initiatives. Nevertheless, in the flurry of critique it is important not to lose sight of the fact that potential institutional challenges associated with harnessing democratised expertise in international risk determination do not by default confer on the alternatives - narrowly-focused science-based approaches or highly technocratic models - any greater credibility or legitimacy. Indeed, the latter may be the more problematic in this regard if by restricting the scope of uncertainties considered or discarding novel viewpoints they (at best) produce overly narrow assessments of risk or (at worst) miss the warning signs of future harms to health or the environment.

At one level, the problems encountered in moving towards democratised risk assessment at the supranational level reflect the fact that international structures have not been designed to accommodate the kind of inputs (particularly the broader participatory inputs) that such approaches require. States, international organisations and experts are all given a voice in existing institutional processes, such as those of the WTO, but it is more difficult to hear from the public in any systematic way, other than via (self-appointed) representatives, such as NGOs. By exposing the resulting legitimacy problems created when particular supranational structures seek to exercise extensive review functions over national risk regulation, discussions of the democratisation of expertise and risk assessment may provide a useful impetus for participatory reforms at the international level. Nonetheless, if the goal is better decision-making on risk, that is, decisionmaking that cognisant of uncertainties, divergent risk framings and real world policy concerns, then it is important that such exercises in democratisation do not become democracy for democracy's sake alone.

In looking across the spectrum of approaches to risk determination offered by science-based, technocratic and democratised models, it is thus crucial that there is a focus on questions of why as well as how, and that "normative discussion" and "tough debates on technological futures" take place as part of decisions to implement any particular approach. ${ }^{52}$ Facilitating such negotiation is what is required to settle on appropriate boundaries between considerations of science and politics in any given situation of risk decision-making. The goal of negotiation should be to ensure acceptance of the boundary eventually selected with as many different audiences as possible, bearing in mind that the broad ramifications of many WTO decisions for daily life may mean that

52 Jasanoff, above n 5, 243. 
this group encompasses not just governments and scientists, but also businesses, NGOs, communities and individuals.

Creating space for inclusive debate to occur around such issues at the international level is likely to prove a more difficult task in some cases than in others. For example, in the case of high-certainty high-consensus risk situations an appropriate science-politics boundary might be negotiated with the direct involvement of fewer participants, given plausible assumptions that scientific representations of risk would be considered credible and legitimate by a range of audiences. At the low-certainty, low-consensus end of the spectrum it will probably be more difficult to satisfy the different expectations of the range of possible audiences for the risk decision. In such cases, it may be more fruitful first to pursue localised or regionalised approaches, perhaps moving over time to a global approach if uncertainty concerns abate and risk framings converge. This is, of course, a more modest vision for supranational risk determination than living in a globalising world might seem to demand. ${ }^{53}$ Yet in evolving forms of supranational risk decision-making it is becoming clear that the "scarce resources" are not those of science and expertise, but rather "legitimacy and trust". ${ }^{54}$ If these take time to build as societies adjust to the new reality of a supranational level of governance, the drive for science-based global risk determination may need to slow its pace so as not to outstrip their evolution.

53 Subsidiarity, regionalisation and similar approaches necessarily compete with goals of harmonisation which have been a primary concern of the WTO.

54 Nowotny, above n 10, 153. 